\title{
Surgical Intervention for Gastrointestinal Foreign Bodies in Adults: A Case Series
}

\author{
Theodoros Syrakos $^{\mathrm{a}}$ Emmanouil Zacharakis ${ }^{\mathrm{b}}$ Polichronis Antonitsis ${ }^{\mathrm{a}}$ \\ Evangelos Zacharakis $^{b}$ Constantinos Spanos ${ }^{a} \quad$ G. Georgantis ${ }^{a}$ \\ Dimitrios Kiskinis ${ }^{a}$ \\ a 4th Academic Surgical Unit, General Hospital Papageorgiou, Aristotle University of Thessaloniki, Thessaloniki, and \\ bSurgical Department, District General Hospital of Veroia, Veroia, Makedonia, Greece
}

\section{Key Words}

Foreign body ingestion $\cdot$ Complications $\cdot$ Surgical

treatment

\begin{abstract}
Objective: The aim of our study was to demonstrate our experience regarding the surgical treatment of complications after foreign body ingestion. Subject and Methods: From 1997 to 2005, we treated 16 adult patients (mean age 44.8 years, range 21-77), who presented with complications after foreign body ingestion. Results: The complications treated were perforation-peritonitis: $\mathrm{n}=7(44 \%)$, intra-abdominal abscess formation: $n=5(31 \%)$, upper gastrointestinal bleeding: $\mathrm{n}=3(19 \%)$ and inflammatory mass formation: $\mathrm{n}=1(6 \%)$ patient. The diagnosis was made intra-operatively in 13 (81.3\%) of the cases. The commonest anatomical position of the perforation was the large bowel, in 7 (43\%) of the cases. Bony food parts were the commonest foreign bodies accidentally swallowed, in 9 (56\%) patients. The median hospital stay was 7 days (2-18), while no death occurred in the postoperative period among the patients of the study. The postoperative morbidity rate was $22.2 \%$. Conclusions: The most common complication after foreign body ingestion was the perforation of the gastrointestinal tract. The risk of perforation was higher when sharp foreign bodies were ingested. The pre-operative diagnosis was difficult, and it was usually achieved intra-operatively.

Copyright $\odot 2008$ S. Karger AG, Basel
\end{abstract}

\section{Introduction and Objective}

Ingestion of foreign bodies is a significant problem that causes surprisingly high morbidity and mortality [1]. Despite the fact that it is reported to be more common in children, especially in patients between 6 months and 6 years of age, foreign body ingestion can also occur among adult patients [2-4]. In the majority of cases, foreign bodies can pass successfully through the proximal oesophageal sphincter and the ileocaecal valve, before they are discharged in the faeces $[2,5,6]$. Endoscopic intervention is the gold standard technique used for the removal of foreign bodies from the gastrointestinal (GI) tract [7]. However, in some cases, foreign body ingestion is followed by life-threatening complications, for which surgical intervention is essential, such as perforation and peritonitis, perforation with secondary abscess formation, GI bleeding, bowel obstruction or even perforation with injury of adjacent viscera $[8,9]$. The aim of this retrospective study was to report our experience after surgical treatment of complications secondary to foreign body ingestion in adult patients.

\section{Subjects and Methods}

From 1997 to 2005, we treated 16 patients who presented with a major complication after foreign body ingestion. The study group consisted of 10 male and 6 female patients with a mean age

\section{KARGER}

Fax +41613061234

E-Mail karger@karger.ch

www.karger.com
(C) 2008 S. Karger AG, Basel

$1011-7571 / 08 / 0174-0276 \$ 24.50 / 0$

Accessible online at:

www.karger.com/mpp
Dr. Emmanouil Zacharakis, MD, PhD, Locum Consultant General Surgeon Department of Biosurgery and Surgical Technology, Imperial College London 10th Floor, QEQM Wing, St. Mary's Campus, Praed Street, London W2 1NY (UK) Tel. +44 77722 77820, Fax +442078867950

E-Mail manoszacharakis@hotmail.com or e.zacharakis@imperial.ac.uk 
of 44.8 years (range $21-77)$. The majority of the patients $(n=13)$ presented to the accident and emergency department of our hospital complaining of acute abdominal pain. The remaining 3 were referred from the endoscopic department of the hospital after failure of endoscopic removal of the foreign body from the GI tract. The main presenting symptoms were abdominal pain: $\mathrm{n}=13$; $\mathrm{fe}-$ ver: $\mathrm{n}=10$; melaena: $\mathrm{n}=3$; tenesmus: $\mathrm{n}=2$, and vomiting: $\mathrm{n}=7$.

The imaging techniques used for the diagnostic approach of the patients included plain abdominal and chest X-ray films, abdominal ultrasound scan and computed tomography (CT) scan. In 3 of the cases, endoscopic approach was attempted prior to the surgical intervention.

\section{Results}

Despite the wide variety of diagnostic tools used, accurate pre-operative diagnosis could not be established in most of the patients $(n=13)$ and, therefore, explorative laparotomy was required.

Table 1. Anatomical position of the complication

\begin{tabular}{lcc}
\hline Anatomical position & \multicolumn{2}{l}{ Cases } \\
\cline { 2 - 3 } & $\mathrm{n}$ & $\%$ \\
\hline Large bowel & 7 & 43 \\
Small bowel & 5 & 31 \\
Duodenum & 2 & 13 \\
Stomach & 2 & 13 \\
\cline { 2 - 3 } Total & 16 & 100 \\
\hline
\end{tabular}

The complications after foreign body ingestion included perforation-peritonitis: $\mathrm{n}=7$ (44\%), intra-abdominal abscess formation: $\mathrm{n}=5$ (31\%), upper GI bleeding: $\mathrm{n}=3$ (19\%) and inflammatory mass formation: $\mathrm{n}=1$ (6\%) patient.

The commonest anatomical position of the perforation was found to be the large bowel, in 7 (43\%) of the cases (table 1). Bony food parts were found to be the commonest foreign bodies accidentally swallowed by the patients of our study. The foreign bodies detected were bony parts: $n=9(56 \%)$; toothpick: $n=5(31 \%)$, and wire: $n=2$ (13\%). In all but 2 of the patients, the foreign body ingestions occurred accidentally during feeding. The remaining 2 patients, who had a psychiatric background, swallowed the foreign bodies on purpose.

The type of operation performed was chosen according to the intra-operative findings and the anatomical position of the complication. In 8 (50\%) of the cases, simple closure of the perforated bowel, peritoneal washout and drainage of the peritoneal cavity was adequate treatment, but in the remaining cases, more complex procedures were required. The foreign body, the anatomical position of the complication, and the type of operation performed for each case are presented in table 2.

No death occurred among the patients; complications during the postoperative period occurred in 4 (25\%) of the patients. The complications consisted of wound infection: $n=2$, pneumonia: $n=1$, and bile fistula formation: $\mathrm{n}=1$ patient, who had undergone duodenotomy and suturing of a bleeding point at the second part of the du-

Table 2. Detailed presentation of the cases

\begin{tabular}{|c|c|c|c|c|}
\hline Patient & Anatomical position & Complication & Foreign body & Management \\
\hline 1 & caecum & perforation - abscess & toothpick & appendicectomy - suturing of perforation \\
\hline 2 & transverse colon & perforation - abscess & toothpick & suturing of perforation \\
\hline 3 & ileum & perforation - peritonitis & toothpick & appendicectomy - suturing of perforation \\
\hline 4 & Meckel's diverticulum & perforation - peritonitis & bone & appendicectomy - Meckelectomy \\
\hline 5 & transverse colon & perforation - abscess & bone & omentectomy - ileostomy \\
\hline 6 & ileum & perforation - peritonitis & bone & suturing of perforation \\
\hline 7 & sigmoid colon & perforation - peritonitis & bone & suturing of perforation \\
\hline 8 & duodenum $^{1}$ & bleeding & bone & suturing of bleeding point \\
\hline 9 & stomach $^{1}$ & bleeding & wire & suturing of bleeding point \\
\hline 10 & jejunum & perforation - peritonitis & toothpick & $\begin{array}{l}\text { suturing of perforation - appendicectomy } \\
\text { and Meckelectomy }\end{array}$ \\
\hline 11 & duodenum & perforation - peritonitis & bone & suturing of perforation \\
\hline 12 & ileum & perforation - peritonitis & wire & suturing of perforation \\
\hline 13 & right colon flexure & inflammatory mass on the right colon flexure & bone & removal of inflammatory mass, omentectomy \\
\hline 14 & appendix vermiformis & perforation - abscess & toothpick & appendicectomy \\
\hline 15 & stomach $^{1}$ & bleeding & bone & suturing of bleeding point \\
\hline 16 & sigmoid colon & perforation - abscess & bone & Hartmann's sigmoidostomy \\
\hline
\end{tabular}

${ }^{1}$ Referred from endoscopy. 
odenum. The latter was successfully treated conservatively as the fistula subsided after total parenteral nutrition for 15 days.

The median hospital stay was 7 days (2-18) and the median operation time was 70 min (range 35-175).

\section{Discussion}

Foreign body ingestion is a major problem, as it is reported to be accompanied by remarkably high morbidity and mortality rates [10]. Approximately 1,500-1,600 people die each year in the USA of complications after foreign body ingestion [10].

Most of the ingested foreign bodies pass successfully through the GI tract and get discharged with the faeces. Therefore, in patients who present with accidental foreign body ingestion, daily observation with abdominal $\mathrm{X}$-ray is adequate, as long as these bodies are radiopaque and blunt. Sharp objects (e.g. needles, toothpicks) are more likely to infiltrate or perforate the bowel wall. Therefore, all sharp foreign bodies must be removed before passing the stomach, as it is reported that $15-35 \%$ of them will perforate the bowel, usually around the ileocaecal valve [11, 12]. According to Webb [13], if a sharp foreign object has not advanced in the GI tract after 3 days, then surgical intervention should be considered, and if the patient becomes symptomatic, then surgical intervention is mandatory. Ingestion of sharp foreign bodies is accompanied by higher morbidity and mortality rates, compared to the rest of the foreign body groups [14-16]. In our study all complications were caused by sharp foreign bodies.

Foreign body ingestions are more common in children, as they tend to place foreign bodies in their mouth. This results in the accidental ingestion of them and their impaction in different sites of the GI tract, with the oesophagus being the commonest site reported [17-19]. Odelowo and Komolafe [19] have observed a physiological stenosis in the lower part of the cricopharyngeal muscle in children. It is more likely that the ingested foreign body can pass through the GI tract without causing any complications in children than in adults [20]. However, we could not compare our findings with those of children because our study group comprised only adult patients.

A large variety of ingested foreign bodies have been reported with a majority of them being metallic objects instead of bony elements of food as in our study [21]. The commonest impaction site of the GI tract for foreign bodies in adults was the oesophagus $[10,22]$. The other com- mon reported impaction site was the splenic flexure [23]. In our study, the commonest site of the complications was the large bowel. Furthermore, the appendix and Meckel's diverticulum also appeared to be potential sites of perforation due to foreign bodies.

Diagnosis of radiopaque foreign bodies is not difficult, since plain chest and abdominal X-rays can be sufficient, but detection of radiolucent foreign bodies can be difficult; oral contrast studies may be useful in these cases. In case of a perforation, abdominal ultrasound and CT scan have proven to be very useful [24]. In the rare cases of duodenal perforation, it is difficult to diagnose it quickly and accurately, if the perforation is not accompanied by symptoms of generalized peritonitis or by abscess formation. The use of double-contrast X-rays is necessary for the diagnosis of such perforations [9]. In our study, most of the foreign bodies were radiolucent. Moreover, abdominal ultrasound and CT scan were not useful in detecting the cause of the GI perforation in our series, hence explorative laparotomy was required.

\section{Conclusion}

The most common complication after foreign body ingestion seems to be the perforation of the GI tract, but it is not always complicated by generalized peritonitis. The risk of perforation seems to be higher when sharp foreign bodies are ingested. The pre-operative diagnosis is difficult and despite the wide range of imaging methods, the diagnosis of foreign body complication is usually achieved during operation, especially when the foreign body is radiolucent.

References

1 Webb WA: Foreign bodies in the upper gastrointestinal tract; in Taylor MB (ed): Gastrointestinal Emergencies. Baltimore, Williams \& Wilkins, 1992, pp 1-12.

$\checkmark 2$ Webb WA: Management of foreign bodies of the upper gastrointestinal tract: update. Gastrointest Endosc 1995;41:39-51.

3 Cheng W, Tam PK: Foreign-body ingestion in children: experience with 1265 cases. J Pediatr Surg 1999;34:1472-1476.

4 Hachimi-Idrissi S, Corne I, Vandenplas Y: Management of ingested foreign bodies in childhood: our experience and review of the literature. Eur J Emerg Med 1998;5:319323.

5 Nandi P, Ong GB: Foreign body in the oesophagus: review of 2394 cases. Br J Surg 1978;65:5-9. 
6 Vizcarrondo FJ, Brady PG, Nord HJ: Foreign bodies of the upper gastrointestinal tract. Gastrointest Endosc 1983;29:208-210.

7 Mosca S, Manes G, Martino R, Amitrano L, Bottino V, Bove A: Endoscopic management of foreign bodies in the upper gastrointestinal tract: report on a series of 414 adult patients. Endoscopy 2001;33:692-696.

8 Ginsberg GG: Management of ingested foreign objects and food bolus impactions. Gastrointest Endosc 1995;41:33-38.

-9 Toyonaga T, Shinohara M, Miyatake E, Ouchida K, Shirota T, Ogawa T: Penetration of the duodenum by an ingested needle with migration to the pancreas: report of a case. Surg Today 2001;31:68-71.

10 Bloom RR, Nakano PH, Gray SW, Skandalakis JE: Foreign bodies of the gastrointestinal tract. Am Surg 1986;52:618-621.

-11 Maleki M, Evans WE: Foreign body perforation of the intestinal tract. Arch Surg 1970; 101:475-477.
12 Macmanus JE: Perforation of the intestine by ingested foreign body. Am J Surg 1941;53: 393-400.

13 Webb WA: Management of foreign bodies of the upper gastrointestinal tract. Gastroenterology 1988;94:204-216.

14 Roseb W, Jossen M: Fibro-endoscopic foreign body removal from the upper gastrointestinal tract. Endoscopy 1972;4:193-197.

15 Ricote GC: Fiberendoscopic removal of foreign bodies of the upper part of the gastrointestinal tract. Surg Gynecol Obstet 1985;160: 499-504.

16 Carp L: Foreign bodies in the intestine. Ann Surg 1972;85:575-591.

17 Gill GS: A six-month review of foreign bodies in casualty department of Kenyatta $\mathrm{Na}$ tional Hospital, Nairobi. East Afr Med J 1972;49:428-435.

18 Obiako MN: Foreign bodies in the esophagus. Postgrad Doctor 1983;5:382-388.
19 Odelowo EOO, Komolafe OF: Diagnosis, management and complications of esophageal and airway foreign bodies. Int Surg 1990;75:148-154.

20 Vyas K, Sawant P, Rathi P, Das HS, Borse N: Foreign bodies in gut. J Assoc Physicians India 2000;48:394-396.

21 Kelley JE, Leech MH, Carr MG: A safe and cost-effective protocol for the management of esophageal coins in children. J Pediatr Surg 1993;28:898-900.

22 Stack LB, Munter DW: Foreign bodies in the gastrointestinal tract. Emerg Med Clin North Am 1996;14:493-521.

23 McCanse DE, Kurchin A, Hinshaw JR: Gastrointestinal foreign bodies. Am J Surg 1981; 142:335-357.

24 Wunsch R, Zieger B, Darge K, Wunsch C: Foreign body ingestion. Radiologe 1999;39: 472-477. 